\title{
Microstructure of Annona muricata L. Leaves Extract Microcapsules Linked to Physical and Chemical Characteristics
}

\author{
Oscar Jordán-Suárez ${ }^{1}$, Patricia Glorio-Paulet², Leslie Vidal ${ }^{3}$ \\ ${ }^{1}$ Facultad de Ciencia de Alimentos, Universidad Le Cordon Bleu, Lima, Perú \\ ${ }^{2}$ Departamento de Ingeniería de Alimentos y Productos Agropecuarios, Universidad Nacional Agraria La Molina, Lima, Perú \\ ${ }^{3}$ Departamento de Agroindustrias, Universidad de Concepción, Chillán, Chile \\ Email: *oscar.jordan@ulcb.edu.pe
}

How to cite this paper: Jordán-Suárez, O., Glorio-Paulet, P. and Vidal, L. (2018) Microstructure of Annona muricata L. Leaves Extract Microcapsules Linked to Physical and Chemical Characteristics. Journal of Encapsulation and Adsorption Sciences, 8, 178-193.

https://doi.org/10.4236/jeas.2018.83009

Received: August 17, 2018

Accepted: September 22, 2018

Published: September 25, 2018

Copyright (ㅇ 2018 by authors and Scientific Research Publishing Inc. This work is licensed under the Creative Commons Attribution International License (CC BY 4.0).

http://creativecommons.org/licenses/by/4.0/

\begin{abstract}
Microstructure is closely related to techno-functional properties in microencapsulated powders intended to protect bioactive compounds. Soursop leaves provide phytochemicals that need to be protected to ensure their functionality. This investigation aimed to study the microstructure of microcapsules containing soursop leaves extract and its linkage with physical and chemical characteristics of the resulting powder. Microcapsules were prepared by spray drying using gum Arabic and maltodextrin as encapsulating agents at 5 and $10 \%$. Powders were characterized by scanning electron microscopy, particle size analysis, solubility, infrared spectroscopy and encapsulation efficiency. Microphotographs showed spherical shape particles ranging from 0.25 to $13.87 \mu \mathrm{m}$, where the particles morphology depended on the concentration and the type of the encapsulant used. At higher concentration of encapsulant, there was an increase in the sphericity, integrity, size, and surface smoothness of particles. This relationship was inverse for solubility in treatments with gum Arabic. The extract encapsulation was confirmed by Fourier Transform infrared spectroscopy and encapsulation efficiency index, revealing that the treatment with maltodextrin at $10 \%$ showed a better capability for entrapment $(72.12 \%)$. The results evidence that microstructure of microcapsules is closely linked to the type and concentration of encapsulant, which in turn determine the physical and chemical characteristics of powders intended for instant drinks solubility and entrapping soursop bioactive compounds.
\end{abstract}

\section{Keywords}

Soursop, Microencapsulation, Microstructure, Spray Drying, Encapsulants 


\section{Introduction}

Soursop (Annona muricata L.) is traditionally used in ethnomedicine by different populations around the world [1]. Recently, the consumption of its leaves as extracts has been massively increased due to their therapeutic properties supported by a number of studies [2] [3] [4] [5] [6], which has led its commercialization in various presentations. These properties are attributed to the phytochemicals present in different parts of the plant [7], being mainly acetogenins, alkaloids and phenolic compounds [8].

Bioactive phytochemicals are susceptible to fast inactivation or degradation once they are extracted from its original source [9]. In this context, the microencapsulation is an alternative process to increase their stability, protecting them from adverse environmental conditions such as light and oxygen [10] as well as digestive conditions, allowing their distribution and ensuring their absorption at the desired sites [9] [11].

Microencapsulation, which is one of the most used techniques for bioactive compounds conservation, is defined as a process where small particles or drops are surrounded by a cover or embedded in a homogeneous or heterogeneous matrix to generate microscopic capsules with advantageous properties [12]. Among the current encapsulation techniques is the spray drying, which is used due to its low cost and simplicity of operation [13] [14]. During spray drying, drops generated by a nozzle are instantly dehydrated by application of heat; usually, solutions containing the compounds of interest mix with additional ingredients known as encapsulants, which play a structural role. The most effective encapsulating agents for food applications are the polysaccharides [11]. Two of the most commonly used in microencapsulation by spray drying are gum Arabic (GA) and maltodextrin (MD) because of its technological properties [15] [16], both are recognized as GRAS (Generally Recognized as Safe) ingredients. They are colorless, offer high solubility in water, low viscosity in solution, relatively low cost, and ensure an adequate protection of compounds sensitive to oxidation [15] [16] [17] [18] [19].

Depending on the microencapsulation technique and the encapsulants used, it is possible to obtain particles with heterogeneous superficial structure, size, and shape, which lead to a deficient conservation of the compounds of interest [12] [20] [21]. The microparticle structure is determinant for techno-functional properties such as solubility, liberation, or reconstitution of the resulting powder; thus, it is a priority to understand the formation of the microcapsules surface structure in terms of composition [16] [22].

There is no former information about studies on morphology of soursop leaves extract microencapsulated by spray drying. The aim of this investigation was to study the microstructure of microcapsules of hydroalcoholic extract from soursop leaves (Annona muricata L.) microencapsulated via spray drying using gum Arabic and maltodextrin as encapsulants at two different concentrations, and its linkage with physical and chemical properties. 


\section{Materials and Methods}

\subsection{Materials}

The herbal Augusto Weberbauer (MOL) of the Universidad Nacional Agraria La Molina, certified the authenticity of the species under study. The leaves were collected in a farm in Pisco, Ica, Peru (Latitude $13^{\circ} 44.817^{\prime} \mathrm{S}$, Longitude: $76^{\circ} 9.897^{\prime} \mathrm{W}$ ) during December 2016. Ethanol 99.9\% (Merck, Germany) was used for extraction. The encapsulants used were gum Arabic (Nexira food, France) and maltodextrin DE = 15 - 20 (Lihua Starch, China), which were selected in former trials due to its tolerance to ethanolic solutions. Other reagents used were Acetic acid (Merck, Germany), Gallic acid (Sigma-Aldrich, USA), Folin-Ciocalteu reagent (Merck, Germany), and sodium carbonate (Merck, Germany).

\subsection{Preparation of Samples}

The collected fresh leaves were selected, washed with drinking water and dried in absence of sunlight for 10 days (Final humidity $=12 \%$ ). They were previously oven-dried (UM400 Memmert) at $50^{\circ} \mathrm{C}$ until reaching $10 \%$ humidity before grinding. Then, the leaves were ground in a leaf mill (3383-L30 Thomas Scientific) applying a $\mathrm{N}^{\circ} 20$ sieve. The leaves powder was hermetically stored in polyethylene bags until being used.

\subsection{Extraction}

The previously powdered leaves were weighed in Erlenmeyer flasks, mixed with a hydroalcoholic solution (20\% ethanol) at 1:36 rate (mass:volume), and placed in a water bath (AL 25 LAUDA Aqualine) at $70^{\circ} \mathrm{C}$ for 30 minutes. Then, the extraction was stopped by immersing the flasks in a bath with ice. The extract was filtered using a nylon fiber. The filtrate was centrifuged at 2,500 rpm (IEC HN-SII Damon) for 30 minutes.

\subsection{Microencapsulation}

The resulting supernatant from the extraction was mixed with gum Arabic and maltodextrin to obtain solutions at $5 \%$ and $10 \%(\mathrm{w} / \mathrm{w})$. The mixture was homogenized (IKA ${ }^{\circledR}$ T18 Ultra-Turrax ${ }^{\circledR}$ ) at 10,000 and 15,000 rpm for 5 minutes each turn and kept in refrigeration until being used. Mixtures were spray dried in a Mini Spray Dryer B-2 90 (Büchi, Switzerland) with a $1 \mathrm{~mm}$ nozzle at $140^{\circ} \mathrm{C}$, an air flow rate of $32.5 \mathrm{~m}^{3} / \mathrm{h}$, a feeding flow rate of $10 \mathrm{~mL} / \mathrm{min}$ and pump at $10 \%$.

\subsection{Microstructural Analysis}

\section{Morphology study by scanning electron microscopy (SEM)}

The morphology of the dry extract, the pure encapsulants, and the microcapsules was evaluated with a JSM-6380LV (JEOL, Japan) microscope. The powdered samples were placed on the upper surface of metallic stubs covered with Scotch double sided tape and vacuum immobilized using gold (S150, Edwards). Microphotographs were taken at magnifications ranging from 1200 to 20000x. 


\section{Particle Size analysis}

The size was expressed in terms of the volume-weighted mean diameter $(D[4,3])$ which was determined by the estimate of the diameters of more than 650 particles using the software Axio Vision Rel. 4.8 from panoramic photos obtained with SEM. In accordance with Jinapong et al. [23], the D[4,3] was calculated using Equation (1):

$$
D[4,3]=\frac{\sum n_{i} d_{i}^{4}}{\sum n_{i} d_{i}^{3}}
$$

where $n_{i}$ is the number of particles of $d_{i}$ diameter.

\subsection{Qualitative Determination of Extract Encapsulation by Infrared Spectrometry (FTIR)}

To verify the encapsulation process, IR spectrums for the microencapsulated extracts (04 treatments), the sole spray dried extract, and the pure encapsulants were obtained using a portable spectrometer TruDefender FT (Ahura Scientific, USA) diamond point with a resolution of $3 \mathrm{~cm}^{-1}$ from 4000 to $650 \mathrm{~cm}^{-1}$. Before placing the samples (powdered), a correction of air background was made. The peaks were analyzed with the software Resolutions pro 4.0 Varian, Inc.

\subsection{Encapsulation Efficiency of Phenolic Compounds (EE)}

Total phenolic compounds were used as a referential indicator of the amount of phytochemicals in the powders. Encapsulation efficiency for each treatment was determined by quantifying the content of phenolic compounds inside "core" (CPC) and on the surface (SPC) of the microparticles using the Folin-Ciocalteu method adapted from Simon-Brown et al. [24]. Phenolic compounds extraction was performed using the method of Saikia et al. [10]. Aliquots of $100 \mathrm{mg}$ of each powdered extract were mixed with $1 \mathrm{ml}$ of ethanol, acetic acid and water (50:8:42) for the CPC and with $1 \mathrm{ml}$ of ethanol-methanol (1:1) for SPC determinations; then the mixture was stirred in a vortex (Vortex Genie 2, Scientific Industries, Inc.) for 1 minute and then filtered through a $0.45 \mu \mathrm{m}$ syringe filter. $100 \mu \mathrm{L}$ of supernatant was mixed with $100 \mu \mathrm{L}$ of Folin-Ciocalteu reagent diluted in water $(1: 10, \mathrm{v} / \mathrm{v})$; it was left to react for 5 minutes, then $100 \mu \mathrm{L}$ of the aqueous solution of $\mathrm{Na}_{2} \mathrm{CO}_{3}\left(100 \mathrm{~g} \mathrm{l}^{-1}\right)$ was added and leveled with distilled water up to $1200 \mu \mathrm{L} .30$ minutes after the reaction, the absorbance was measured on $120 \mu \mathrm{L}$ at $726 \mathrm{~nm}$ using a microplate spectrophotometer (PowerWave XS2 Biotek). The total content of phenolic compounds was calculated using Equation (2) from a standard curve of Gallic acid solution (1 to $10 \mu \mathrm{g} \mathrm{ml}^{-1}$ ) with a correlation coefficient of $\mathrm{R}^{2}=0.999$.

$$
A=31.401 \times C-0.0001
$$

where $A$ is the absorbance at $726 \mathrm{~nm}$ and $C$ is the concentration in $\mathrm{mg} / \mathrm{mL}$.

The encapsulation efficiency was calculated using the Equation (3): 


$$
E E(\%)=\left(\frac{C P C-S P C}{C P C}\right) \times 100
$$

\subsection{Powders Solubility (SBT)}

The solubility of the microencapsulated extracts was determined according to the adapted method from De Souza et al. [25] as described below. In a falcon tube, $0.5 \mathrm{~g}$ of the sample was mixed with $50 \mathrm{~mL}$ of distilled water and then stirred in an orbital table (TOS-40BOFD, MRC) at $100 \mathrm{rpm}$ for 30 minutes. Then, it was centrifuged at $3000 \mathrm{rpm}$ for 15 minutes (Rotofix 32, Hettich). An aliquot of $25 \mathrm{~mL}$ of the supernatant was oven-dried at $105^{\circ} \mathrm{C}$ in a $50 \mathrm{~mL}$ beaker until reaching a constant weight. The solubility was calculated by the weight difference posterior to evaporation $\left(W_{f}-W_{i}\right)$ corresponding to the solubilized solids of the $25 \mathrm{~mL}$ sample and expressed as a percentage by the Equation (4):

$$
S B T=\left(\frac{W_{f}-W_{i}}{W m}\right) \times 10,000
$$

where $W_{f}$ is the weight of flask plus solids $(\mathrm{g}), W_{i}$ is the weight of empty flask (g) and $W_{m}$ is the weight of the $25 \mathrm{~mL}$ aliquot (g).

\subsection{Statistical Analysis}

EE and SBT data were expressed as the average \pm standard deviation (S.D.) from at least three replicas. The significance of differences between encapsulants and concentrations was evaluated by analysis of variance (ANOVA) using a Randomized Complete Block design considering encapsulants as blocks and concentrations as treatments. The statistical analysis was performed using Microsoft Excel.

\section{Results and Discussion}

\subsection{Microstructural Characterization by SEM}

Morphological characteristics of microparticles such as sphericity, shape and surface (smoothness/roughness), and particle size were examined by analyzing SEM images (Figure 1).

In this study, the microstructure of the spray dried soursop extract without encapsulant and the original structure of commercial encapsulants in powder were used as controls. Each component showed a characteristic microstructure inherent to its chemical nature and as a consequence of the technological process experienced during its elaboration (Figures $1(\mathrm{a})-(\mathrm{c})$ ). The drying operation is a complex process where energy and matter transfer mechanisms take place, causing physical, chemical and structural changes [26] [27], which determine the final characteristics of the powder such as color, appearance, textural and structural properties, sensory attributes like aroma and flavor, as well as nutritional and functional properties [28]. Therefore, it is imperative to use encapsulants of known microstructural quality to understand the mechanism involved in the transformation of liquid extracts into solid particles. Since there are no 


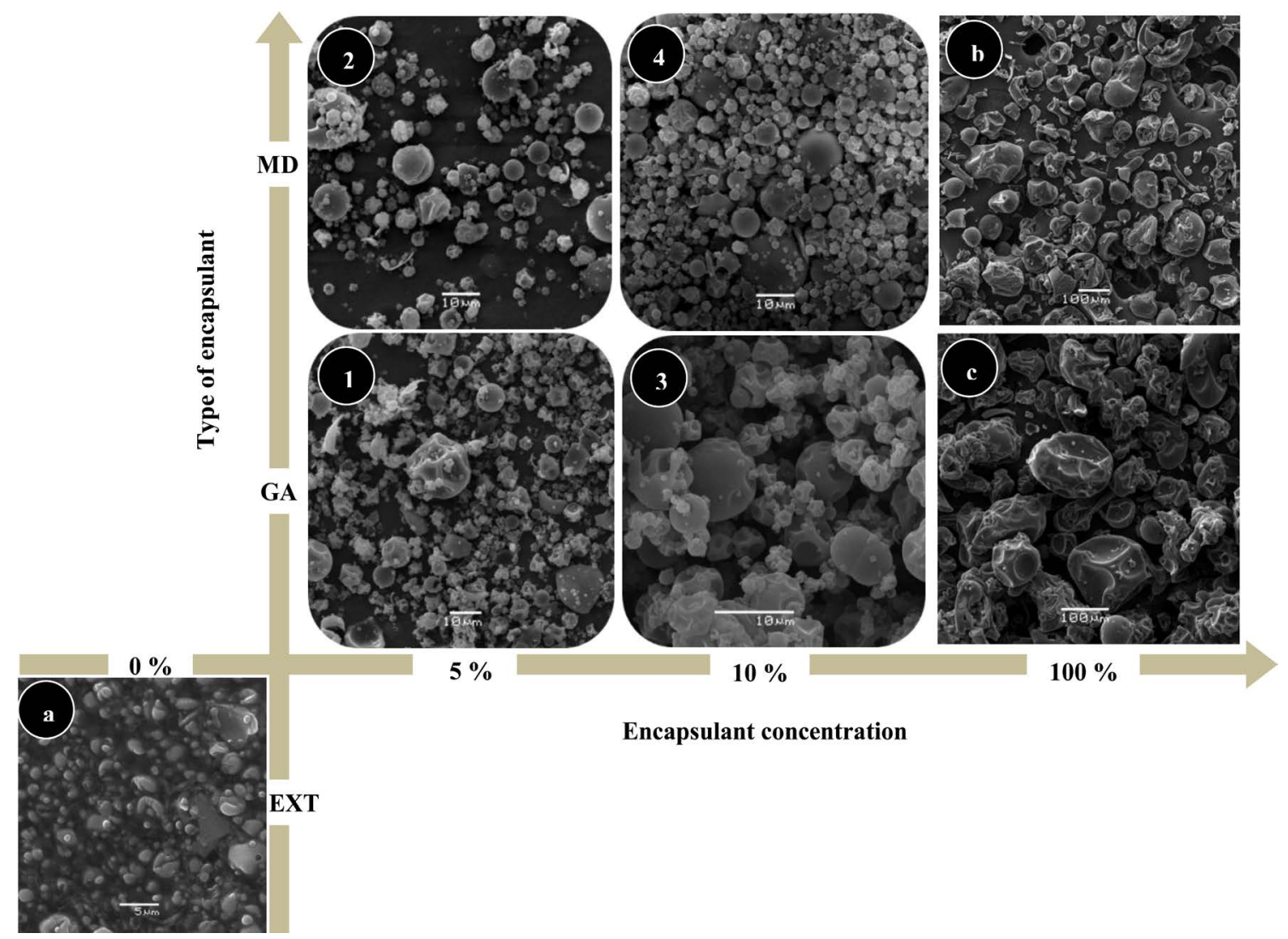

Figure 1. Spray-dried hydroalcoholic extract from soursop leaves (a), maltodextrin powder (b) and gum Arabic powder (c). Microencapsulated soursop leaves extract by spray drying using gum Arabic ((1) and (3)) and maltodextrin ((2) and (4)) at 5 and $10 \%$ respectively.

reference patterns for purity evaluation of the encapsulants, the optimization for obtaining powdered plant extracts and their sub-products might take much more studies.

Visual analysis allowed to understand how the morphology of the supplies gets altered because of the spray drying process. Figures 1(1)-(4) reveals that the entrapment process of the extract into the encapsulants was effective.

In general, the shape of the microparticles was spherical and had a heterogeneous size. The sphericity and the heterogeneity in size is characteristic of the spray drying process [17] [21] [29] but depending in turn on the type and concentration of the encapsulant used [19] [30].

The particles with MD (Figure 1(2) and Figure 1(4)) were more spherical than those with GA (Figure 1(1) and Figure 1(3)). The same has been observed using GA in comparison with MD [24]; according to Fernandes et al. and Janiszewska [31] [32], it is due to the elasticity that MD offers during the drying process; by contrast Dib Taxi et al. [33] indicate that the extracts encapsulated with GA acquire a similar morphology to those of pure GA.

With both encapsulants there is a greater proportion of spherical particles when a concentration of $10 \%$ is used. This verifies that a greater concentration of encapsulant increases the number of spherical particles mainly with MD; simi- 
larly, Simon-Brown et al. [24] reported a greater incidence of spherical particles in Zingiber officinale extracts microencapsulated with MD; $\mathrm{Li}$ et al. [29] also mention that the shrinkage degree diminished as a consequence of the increase of encapsulant concentration in fish oil microcapsules.

From the techno-functional point of view, the particles with a rough surface are more sensitive to oxidation reactions compared with those with a smooth surface due to their greater superficial areas [34]. In the same way, a smooth surface diminishes the gas permeability, improving the protection and retention of the nucleus [24] [29] [35]. Additionally, obtaining microcapsules with a smooth surface enhances the flow characteristics of the material [21].

According to Table 1, the microcapsules sizes varied from 0.25 to $13.87 \mu \mathrm{m}$ and correspond to the range of microparticles $(0.2$ to $5000 \mu \mathrm{m})$ reported by Silva et al. [36]. The relatively small size of the particles could be related to the nature of the solvent used since ethanol would reduce the superficial tension of the solution and would contribute to the formation of small size drops during the aspersion [37]. Having particles with small size is advantageous since it favors solubility.

With both encapsulants, there was an increment of the particle diameter when the encapsulant concentration was increased. Additionally, the particles with GA tended to show a slightly larger size in comparison to those prepared using MD, as has been reported in similar studies [24] [31].

The drying temperature is determinant since significantly influences the conservation of thermosensitive bioactive compounds [19], as well as in the size, shape, and surface of the particles [38]. It should be noted that a high rugosity is characteristic of particles produced by spray drying at low drying temperatures [38] [39]. On the contrary, high temperatures are advantageous for obtaining particles with a smooth surface and with a greater diameter [21] [38] [40]. However, having previously considered the same drying temperature for all the treatments allowed to understand the mechanism of transformation of drops into microparticles and their differences associated with the kind and concentration of encapsulants.

\subsection{Formation of Defective Particles during Spray Drying}

Drop formation into microcapsule and proposed mechanisms to explain in a graphical way how some defective particles were formed during spray drying are

Table 1. Volume-weighted mean diameter and size of microcapsules.

\begin{tabular}{rcc}
\hline Treatment & $\mathrm{D}[4,3](\mu \mathrm{m})$ & Size range $(\mu \mathrm{m})$ \\
\hline EXT GA 5\% & 6.97 & $0.28-13.87$ \\
EXT GA 10\% & 7.51 & $0.25-11.21$ \\
EXT MD 5\% & 7.05 & $0.29-12.86$ \\
EXT MD 10\% & 7.36 & $0.30-13.43$ \\
\hline
\end{tabular}


presented in Figure 2, which are coincident with Nandiyanto \& Okuyama, and Walton [41] [42].

During the formation of the microparticle a given thickness of the solid surface (Shell) is needed to give it mechanical resistance to avoid disruption [43], which is achieved by the concentration of the encapsulant and the processing conditions; a high porosity and permeable nature of the particle structure allows the flow of water, water vapor and possibly the dissolved gases from the interior to the surface with a minimum resistance, so minimizing the internal pressure and the distention of the particles (inflation) [42], otherwise if the internal pressure were superior as a consequence of an outside impervious layer, an expansion and explosion would occur.

The fragmentation of particles (Figure 2(a)) was a recurrent fault in all the treatments, but evidently it was lower at higher concentration of encapsulant; lack of integrity is related to the nature of the encapsulant material and is also associated to high drying temperatures, which produce an excessive water evaporation and a quick expansion of the particle [38] [40] causing breaking off and formation of superficial holes.

The microparticles with GA at 5\% showed to have experienced a "ballooning" phase tending to breakage after having overreached their extension; in spite of this phenomenon was visually lower at highest encapsulant concentrations, it was also shown the presence of post rupture particle remainders. The incidence of breaking off is an indicator of the microencapsulation process efficiency [44],

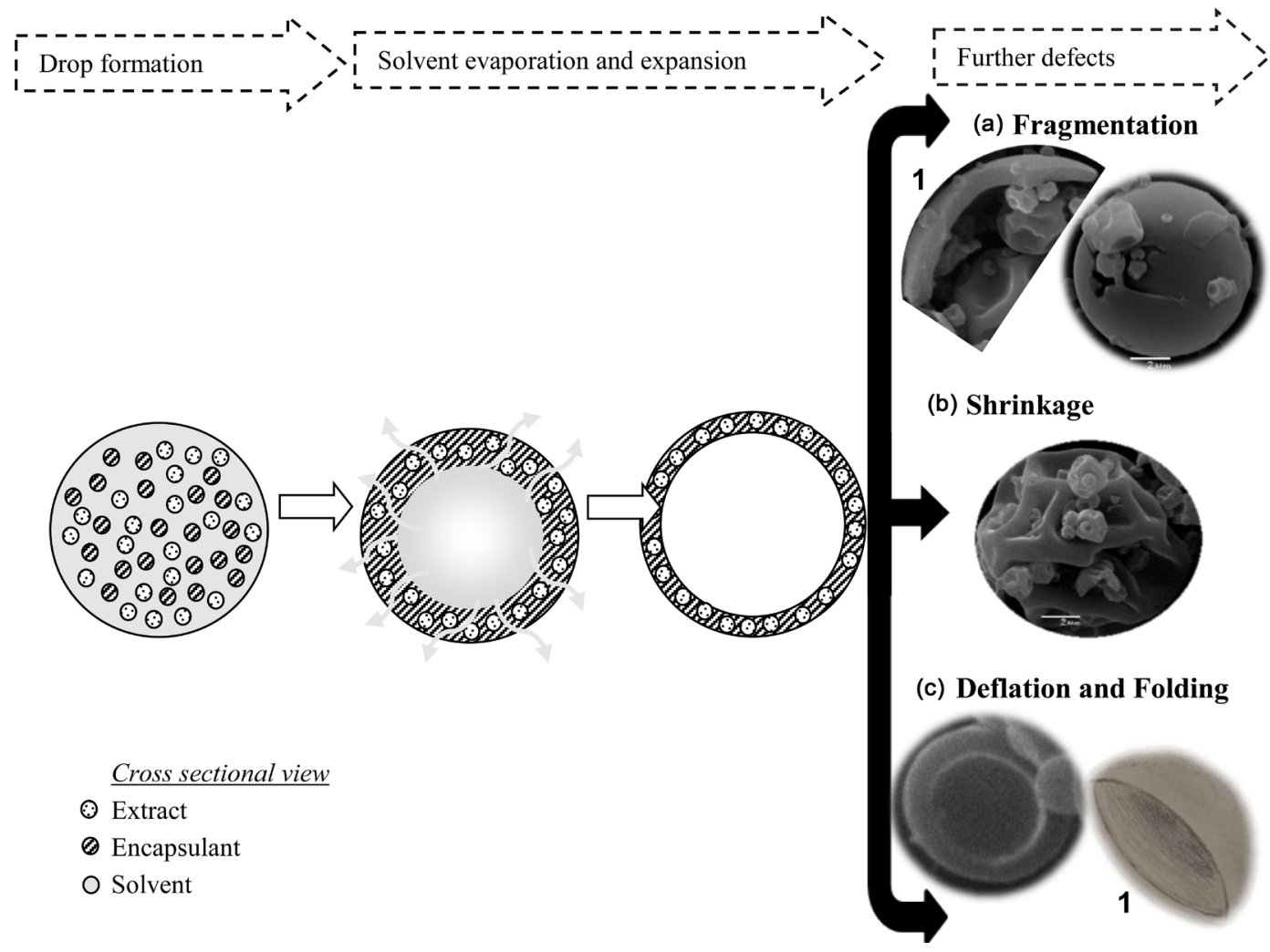

Figure 2. Formation of defective particles during spray drying. 
being both inversely proportional.

Microparticles with GA showed a predominant rough surface (Figure 2(b)), which is associated with a higher degree of shrinkage; the dented structures can be due to a fast loss of moisture during the first stages of the drying process and an immediate subsequent cooling that causes a contraction of the drops [34] [45]. A rough surface morphology induces agglomeration of particles which affects flow properties.

Mushroom hat type microparticles can be observed in the microphotographs of extract with 10\% GA (Figure 2(c)); similarly, Janiszewska \& Włodarczyk [46] reported microphotographs from beetroot pigment encapsulated with MD by spray drying, where different stages of what would happen during the formation of these particles can be seen. This suggests that they come from particles which have expanded (without breaking) and they lose internal pressure, producing a deflation followed by a folding in half (Figure 2(c1)).

It is not evident the existence of an independent nucleus (Figure 2(a1)), suggesting that the extract has fused with the matrix making an external wall with a hollow center which is greater while more spherical is the particle; the same behavior has been observed in microparticles of anthocyanin encapsulated using GA/MD; this type of morphology, where the nucleus is homogeneously distributed throughout the wall material, is categorized as multiple core structure [18] or matrix type [47]; simirlaly, Kim \& Morr [48] reported spherical hollow particles surrounded by porous walls and with surface indentations when using GA as encapsulant.

Factors that influence the formation of hollow particles are a rapid evaporation rate [41] and the nature of the solvent [37]; in this case, a binary phase was used as solvent (ethanol-water). According to Walton [42], if the evaporation of volatile solvent exceeds the speed of diffusion of the liquid through the particle structure, a hollow particle with an internal bubble is formed.

One of the primordial properties of encapsulated powder intended for direct human consumption is its easy reconstitution which will depend on the size, density, porosity, superficial charge, superficial area of the particle, and the presence of amphipathic substances [49]. In addition to the technological criterion, in a broader approach, it is necessary that the microcapsules protect the bioactive compounds from gastrointestinal conditions in such a way that their liberation in a specific site is accomplished [9].

Therefore, it is necessary to optimize the spray drying conditions (type and concentration of the encapsulant, type of nozzle, entrance temperature, air speed, among others), depending on the expected use of the product, taking into account the greatest number of variables with significant effect, which is achieved through a previous screening.

\subsection{Qualitative and Quantitative Confirmation of Microencapsulation}

\section{IR spectrums}

The infrared spectrum of the encapsulant materials, the pure spray-dried ex- 
tract, and the microencapsulated extracts are presented in Figure 3, which reveals the types of molecules they are made of.

All the spectra showed a common band of absorption at the wavelength of $3300 \mathrm{~cm}^{-1}$ (Figure 3), which is characteristic of the hydroxyl group $(-\mathrm{OH})$ and a water content indicator of the samples; similarly, all the spectra have in common a peak around $900 \mathrm{~cm}^{-1}$ which corresponds to $\mathrm{C}-\mathrm{H}$ bonds. The pure dry extract spectrum shows typical absorption bands (molecular fingerprint) in the region between $1700-1400 \mathrm{~cm}^{-1}$; these bands practically disappear in the microencapsulated extracts which indicate a good encapsulation process as described by Medina-Torres et al. [50]. The region ranging from 1630 to $1590 \mathrm{~cm}^{-1}$ is characteristic of phenolic compounds and alkaloids [51].

Both encapsulants reduced the band intensity characteristic of the extract (peaks at 1585 and $1507 \mathrm{~cm}^{-1}$ ); however, unlike MD, the gum Arabic spectrum shows a peak (at around $1600 \mathrm{~cm}^{-1}$ ) very closely located to the characteristics peaks of extract, which has also been identified by Bouaziz et al. [52] for commercial gum Arabic and may be related to amides bonds from protein nature [53]. These results confirm the presence of bioactive compounds inside the microcapsules.

\section{Encapsulation efficiency of phenolic compounds}

Significant differences were found by analyzing the four treatments (Table 2), demonstrating that the phenolic compounds were encapsulated in different degrees in the matrix under the study conditions.

In this study, percentages of EE varied from $53.46 \%$ to $72.12 \%$; the values of efficiency increase when the concentration of the encapsulant increases, and it is higher in samples with MD, trend observed earlier by Saikia et al. [10], who also

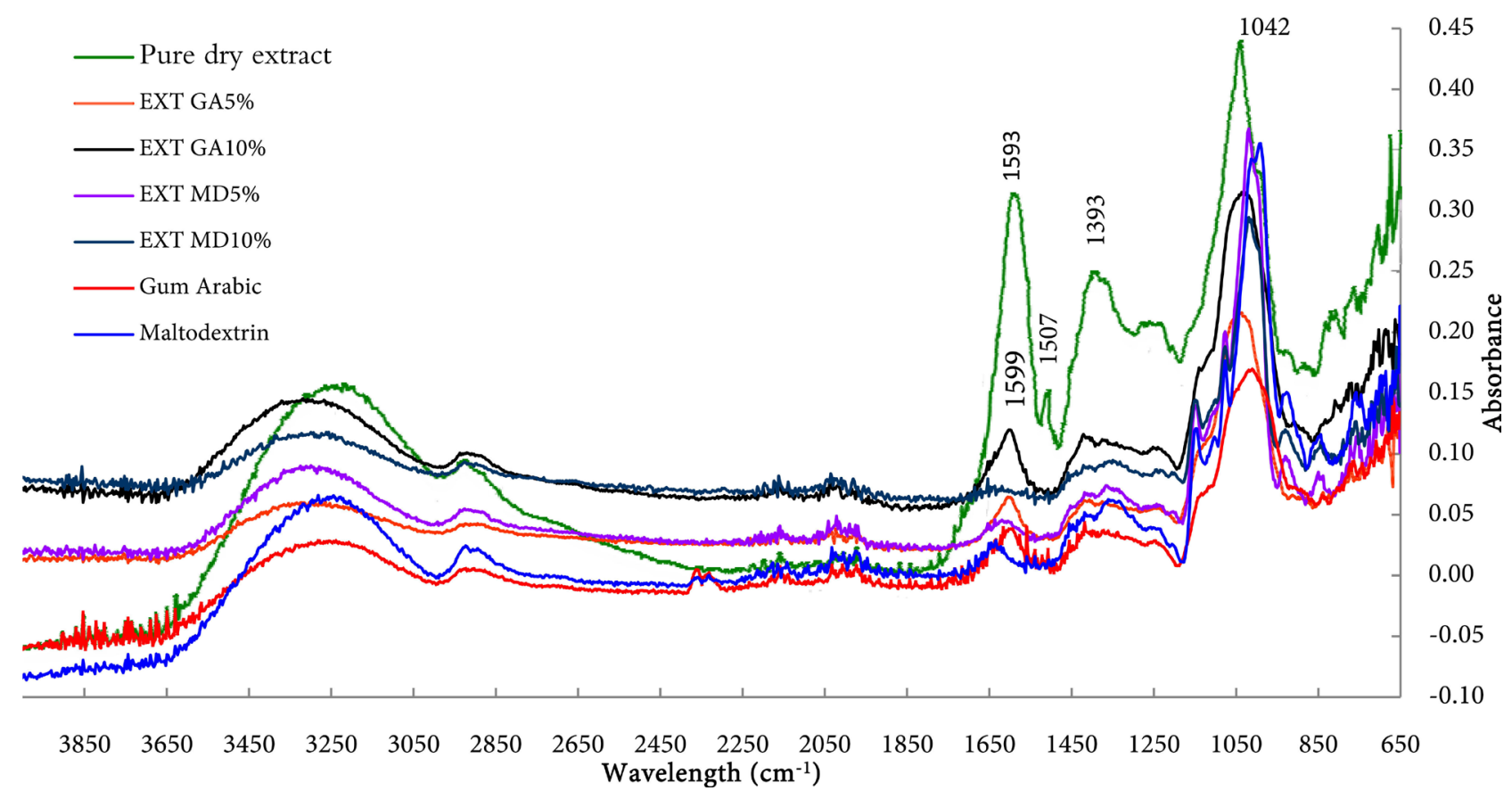

Figure 3. Infrared spectra of treatments with MD and GA and the original supplies. 
Table 2. Encapsulation efficiency and solubility values.

\begin{tabular}{ccc}
\hline Samples & EE $(\%)$ & Solubility \\
\hline EXT GA 5\% & $53.46 \pm 1.931 \mathrm{Aa}$ & $93.23 \pm 0.991 \mathrm{Aa}$ \\
EXT GA 10\% & $64.76 \pm 1.461 \mathrm{Ab}$ & $88.49 \pm 0.731 \mathrm{Ab}$ \\
EXT MD 5\% & $54.10 \pm 0.992 \mathrm{Ba}$ & $98.15 \pm 0.632 \mathrm{Bc}$ \\
EXT MD 10\% & $72.12 \pm 1.102 \mathrm{Bc}$ & $97.38 \pm 0.992 \mathrm{Bc}$ \\
\hline
\end{tabular}

Averages with different capital letters and low case letters in each column indicate a significant difference $(\mathrm{p}$ $\leq 0.05$ ) between blocks and treatments, respectively.

reported values from $63 \%$ to $79 \%$ using MD. Additionally, it was observed that the value for treatment with GA at $5 \%$ becomes equivalent to the treatment with $\mathrm{MD}$ at $5 \%$, but $\mathrm{EE}$ increases significantly with $\mathrm{MD}$ at $10 \%$.

Considering that the extract is a mixture of compounds with unique properties this variability between values of EE is partially explained to be due to the nature of the metabolite and its affinity with the matrix [54], and it is also attributable to the susceptibility of the phenolic compounds during the spray drying process [10] [55] [56].

\subsection{Solubility}

Solubility of microencapsulated powders ranged from $88.5 \%$ to $98.2 \%$ (Table 2), showing significant differences related to the type and concentration of the encapsulant, being the solubility greater when using MD. On the other hand, depending on the type of encapsulant material used there may not be any significant difference between them according to Kuck \& Noreña [56], who used GA, PHGG (guar gum partially hydrolyzed) and PD (polydextrose). Additionally, it was found that the solubility decreased as the concentration of encapsulant was increased. This behavior in solubility would be associated to the particle size since at smaller size the availability for hydration surface will be greater [56]; coincidentally the treatments with higher solubility ( $5 \%$ of encapsulant) exhibited smaller particle size.

\section{Conclusion}

The encapsulation of soursop dry leaves extract by spray drying was achieved, getting microparticles of spherical shape and heterogeneous size $(0.25-13.43$ $\mu \mathrm{m})$. The morphology of the microparticles depended on the concentration (5 and $10 \%$ ) and type of the encapsulant (GA and MD), giving a positive correlation between the encapsulant concentration and the microparticles sphericity, mainly for MD. Also, the powder solubility was greater using MD, but inversely proportional to the concentration of the encapsulant, which is associated with the particle size. The extract encapsulation was qualitative confirmed via FTIR spectroscopy. Encapsulation efficiency essays showed that the treatment with $\mathrm{MD}$ at $10 \%$ presented a greater performance for encapsulating phenolic compounds originally existing in the extract. The characterization of the encapsu- 
lated extract is a starting point in the search of its application in food matrixes.

\section{Acknowledgements}

The authors thank the partial financing provided by the Ministry of Education of Peru (MINEDU): Project for the strengthening of doctoral programs at UNALM "Food Science" CONV-000179-2015-FONDECYT-DE, to the Pacific Alliance scholarship program that allowed the use of facilities provided by the Center of Spectroscopy and Electron Microscopy of University of Concepcion (CESM). We also thank Dr. Luis Rodríguez-Saona for the support given for the use of a portable FTIR spectrometer.

\section{Conflicts of Interest}

The authors declare no conflicts of interest regarding the publication of this paper.

\section{References}

[1] De Feo, V. (1992) Medicinal and Magical Plants in the Northern Peruvian Andes. Fitoterapia, 63, 417-440.

[2] Quispe, A., Zavala, D., Rojas, J., Posso, M. and Vaisberg, A. (2006) Efecto citotóxico selectivo in Vitro de muricin H (acetogenina de Annona muricata) en cultivos celulares de cáncer de pulmón. Revista Peruana de Medicina Experimental y Salud Pública, 23, 265-269.

[3] Arroyo, J., Martínez, J., Ronceros, G., Palomino, R., Villarreal, A., Bonilla, P., Palomino, C. and Quino, M. (2009) Efecto hipoglicemiante coadyuvante del extracto etanólico de hojas de Annona muricata L (guanábana), en pacientes con diabetes tipo 2 bajo tratamiento de glibenclamida. Anales de La Facultad de Medicina, 70, 163-167. https://doi.org/10.15381/anales.v70i3.934

[4] Solís-Fuentes, J.A., Hernández-Medel, M.R. and Durán-de-Bazúa, M.C. (2011) Soursop (Annona muricata L.) Seeds, Therapeutic and Possible Food Potential. In: Preedy, V.R., Watson, R.R. and Patel, V.B., Eds., Nuts and Seeds in Health and Disease Prevention, Academic Press, London, 1045-1052. https://doi.org/10.1016/B978-0-12-375688-6.10124-0

[5] Torres, M.P., Rachagani, S., Purohit, V., Pandey, P., Joshi, S., Moore, E.D., Johansson, S.L., Singh P.K., Ganti, A.K. and Batra, S.K. (2012) Graviola: A Novel Promising Natural-Derived Drug that Inhibits Tumorigenicity and Metastasis of Pancreatic Cancer Cells in Vitro and in Vivo through Altering Cell Metabolism. Cancer Letters, 323, 29-40. https://doi.org/10.1016/j.canlet.2012.03.031

[6] Syed Najmuddin, S.U.F., Romli, M.F., Hamid, M., Alitheen, N.B. and Abd Rahman, N.M.A.N. (2016) Anti-Cancer Effect of Annona Muricata Linn Leaves Crude Extract (AMCE) on Breast Cancer Cell Line. BMC Complementary and Alternative Medicine, 16, 1-20. https://doi.org/10.1186/s12906-016-1290-y

[7] de Q. Pinto, A.C., Cordeiro, M.C.R., De Andrade, S.R.M., Ferreira, F.R., De C. Filgueiras, H.A., Alves, R.E. and Kinpara, D.I. (2005) Annona Species. In: Williams, J.T., Smith, R.W., Hughes, A., Haq, N. and Clement, C.R., Eds., Fruits for the Future 5: Annona species, International Centre for Underutilised Crops, Southampton, 263.

[8] Coria-Téllez, A.V., Montalvo-Gónzalez, E., Yahia, E.M. and Obledo-Vázquez, E.N. 
(2015) Annona muricata: A Comprehensive Review on Its Traditional Medicinal Uses, Phytochemicals, Pharmacological Activities, Mechanisms of Action and Toxicity. Arabian Journal of Chemistry, 11, 662-691. https://doi.org/10.1016/j.arabjc.2016.01.004

[9] de Vos, P., Faas, M.M., Spasojevic, M. and Sikkema, J. (2010) Encapsulation for Preservation of Functionality and Targeted Delivery of Bioactive Food Components. International Dairy Journal, 20, 292-302. https://doi.org/10.1016/j.idairyj.2009.11.008

[10] Saikia, S., Mahnot, N.K. and Mahanta, C.L. (2015) Optimisation of Phenolic Extraction from Averrhoa carambola Pomace by Response Surface Methodology and Its Microencapsulation by Spray and Freeze Drying. Food Chemistry, 171, 144-152. https://doi.org/10.1016/j.foodchem.2014.08.064

[11] Nedovic, V., Kalusevic, A., Manojlovic, V., Levic, S. and Bugarski, B. (2011) An Overview of Encapsulation Technologies for Food Applications Viktor. Procedia Food Science, 1, 1816-1815. https://doi.org/10.1016/j.profoo.2011.09.265

[12] Gharsallaoui, A., Roudaut, G., Chambin, O., Voilley, A. and Saurel, R. (2007) Applications of Spray-Drying in Microencapsulation of Food Ingredients: An Overview. Food Research International, 40, 1107-1121. https://doi.org/10.1016/j.foodres.2007.07.004

[13] Onwulata, C.I. (2013) Microencapsulation and Functional Bioactive Foods. Journal of Food Processing and Preservation, 37, 510-532. https://doi.org/10.1111/j.1745-4549.2012.00680.x

[14] Vaidya, S., Bhosale, R. and Singhal, R.S. (2006) Microencapsulation of Cinnamon Oleoresin by Spray Drying Using Different Wall Materials. Drying Technology, 24, 983-992. https://doi.org/10.1080/07373930600776159

[15] Jafari, S.M., Mahdavi-Khazaei, K. and Hemmati-Kakhki, A. (2016) Microencapsulation of Saffron Petal Anthocyanins with Cress Seed Gum Compared with Arabic Gum through Freeze Drying. Carbohydrate Polymers, 140, 20-25. https://doi.org/10.1016/j.carbpol.2015.11.079

[16] Cano-Chauca, M., Stringheta, P.C., Ramos, A.M. and Cal-Vidal, J. (2005) Effect of the Carriers on the Microstructure of Mango Powder Obtained by Spray Drying and Its Functional Characterization. Innovative Food Science and Emerging Technologies, 6, 420-428. https://doi.org/10.1016/j.ifset.2005.05.003

[17] Carneiro, H.C.F., Tonon, R.V., Grosso, C.R.F. and Hubinger, M.D. (2013) Encapsulation Efficiency and Oxidative Stability of Flaxseed Oil Microencapsulated by Spray Drying Using Different Combinations of Wall Materials. Journal of Food Engineering, 115, 443-451. https://doi.org/10.1016/j.jfoodeng.2012.03.033

[18] Akhavan Mahdavi, S., Jafari, S.M., Assadpoor, E. and Dehnad, D. (2016) Microencapsulation Optimization of Natural Anthocyanins with Maltodextrin, Gum Arabic and Gelatin. International Journal of Biological Macromolecules, 85, 379-385. https://doi.org/10.1016/j.ijbiomac.2016.01.011

[19] Ramírez, M.J., Giraldo, G.I. and Orrego, C.E. (2015) Modeling and Stability of Polyphenol in Spray-Dried and Freeze-Dried Fruit Encapsulates. Powder Technology, 277, 89-96. https://doi.org/10.1016/j.powtec.2015.02.060

[20] Sheu, T.Y. and Rosenberg, M. (1998) Microstructure of Microcapsules Consisting of Whey Proteins and Carbohydrates. Journal of Food Science, 63, 491-494. https://doi.org/10.1111/j.1365-2621.1998.tb15770.x

[21] Tonon, R.V., Brabet, C. and Hubinger, M.D. (2009) Influência da temperatura do ar de secagem e da concentração de agente carreador sobre as propriedades físico-químicas 
do suco de açaí em pó. Ciência e Tecnologia de Alimentos, 29, 444-450. https://doi.org/10.1590/S0101-20612009000200034

[22] Porras-Saavedra, J., Palacios-González, E., Lartundo-Rojas, L., Garibay-Febles, V., Yáñez-Fernández, J., Hernández-Sánchez, H., Gutiérrez-López, G. and Alamilla-Beltrán, L. (2015) Microstructural Properties and Distribution of Components in Microparticles Obtained by Spray-Drying. Journal of Food Engineering, 152, 105-112. https://doi.org/10.1016/j.jfoodeng.2014.11.014

[23] Jinapong, N., Suphantharika, M. and Jamnong, P. (2008) Production of Instant Soymilk Powders by Ultrafiltration, Spray Drying and Fluidized Bed Agglomeration. Journal of Food Engineering, 84, 194-205.

[24] Simon-Brown, K., Solval, K.M., Chotiko, A., Alfaro, L., Reyes, V., Liu, C., Dzandu, B., Kyereh, E., Goldson, A., Thompson, I., Xu, Z. and Sathivel, S. (2016) Microencapsulation of Ginger (Zingiber officinale) Extract by Spray Drying Technology. Food Science and Technology, 70, 119-125.

https://doi.org/10.1016/j.lwt.2016.02.030

[25] De Souza, V.B., Thomazini, M., Balieiro, J.C.D.C. and Fávaro-Trindade, C.S. (2015) Effect of Spray Drying on the Physicochemical Properties and Color Stability of the Powdered Pigment Obtained from Vinification Byproducts of the Bordo Grape ( $\mathrm{Vi}$ tis labrusca). Food and Bioproducts Processing, 93, 39-50.

https://doi.org/10.1016/j.fbp.2013.11.001

[26] Sabarez, H.T. (2017) Optimisation of Industrial Food Drying Operation. International Journal of Food and Biosystems Engineering, 2, 1-8.

[27] Sabarez, H.T. (2012) Computational Modelling of the Transport Phenomena Occurring during Convective Drying of Prunes. Journal of Food Engineering, 111, 279-288. https://doi.org/10.1016/j.jfoodeng.2012.02.021

[28] Karam, M.C., Petit, J., Zimmer, D., Djantou, E.B. and Scher, J. (2016) Effects of Drying and Grinding in Production of Fruit and Vegetable Powders: A Review. Journal of Food Engineering, 188, 32-49. https://doi.org/10.1016/j.jfoodeng.2016.05.001

[29] Li, J., Xiong, S., Wang, F., Regenstein, J.M. and Liu, R. (2015) Optimization of Microencapsulation of Fish Oil with Gum Arabic/Casein/Beta-Cyclodextrin Mixtures by Spray Drying. Journal of Food Science, 80, C1445-C1452. https://doi.org/10.1111/1750-3841.12928

[30] Corrigan, O.I. (1995) Thermal Analysis of Spray Dried Products. Thermochimica Acta, 248, 245-258. https://doi.org/10.1016/0040-6031(94)01891-J

[31] Fernandes, R.V.D.B., Borges, S.V. and Botrel, D.A. (2014) Gum Arabic/Starch/Maltodextrin/Inulin as Wall Materials on the Microencapsulation of Rosemary Essential Oil. Carbohydrate Polymers, 101, 524-532.

https://doi.org/10.1016/j.carbpol.2013.09.083

[32] Janiszewska, E. (2014) Microencapsulation of Ginger (Zingiber officinale) Extract by Spray Drying Technology. Powder Technology, 264, 190-196.

https://doi.org/10.1016/j.powtec.2014.05.032

[33] Dib Taxi, C.M.A., De Menezes, H.C., Santos, A.B. and Grosso, C.R.F. (2003) Study of the Microencapsulation of Camu-Camu (Myrciaria dubia) Juice. Journal of Microencapsulation, 20, 443-448. https://doi.org/10.1080/0265204021000060291

[34] Tolun, A., Altintas, Z. and Artik, N. (2016) Microencapsulation of Grape Polyphenols Using Maltodextrin and Gum Arabic as Two Alternative Coating Materials: Development and Characterization. Journal of Biotechnology, 239, 23-33. https://doi.org/10.1016/j.jbiotec.2016.10.001 
[35] Santana, A.A., Cano-Higuita, D.M., De Oliveira, R.A. and Telis, V.R.N. (2016) Influence of Different Combinations of Wall Materials on the Microencapsulation of Jussara Pulp (Euterpe edulis) by Spray Drying. Food Chemistry, 212, 1-9. https://doi.org/10.1016/j.foodchem.2016.05.148

[36] Silva, P.T. da, Fries, L.L.M., Menezes, C.R. de, Holkem, A.T., Schwan, C.L., Wigmann, É.F., Oliveira, J. de. and Silva, C. de B. da. (2014) Microencapsulation: Concepts, Mechanisms, Methods and Some Applications in Food Technology. Ciência Rural, 44, 1304-1311. https://doi.org/10.1590/0103-8478cr20130971

[37] Sadeghi, F., Torab, M., Khattab, M., Homayouni, A. and Garekani, H.A. (2013) Improvement of Physico-Mechanical Properties of Partially Amorphous Acetaminophen Developed from Hydroalcoholic Solution Using Spray Drying Technique. Iranian Journal of Basic Medical Sciences, 16, 1100-1108.

[38] Alamilla-Beltrán, L., Chanona-Pérez, J.J., Jiménez-Aparicio, A.R. and Gutiérrez-Lopez, G.F. (2005) Description of Morphological Changes of Particles along Spray Drying. Journal of Food Engineering, 67, 179-184. https://doi.org/10.1016/j.jfoodeng.2004.05.063

[39] Lacerda, E.C.Q., Calado, V.M.D.A., Monteiro, M., Finotelli, P.V., Torres, A.G. and Perrone, D. (2016) Starch, Inulin and Maltodextrin as Encapsulating Agents Affect the Quality and Stability of Jussara Pulp Microparticles. Carbohydrate Polymers, 151, 500-510. https://doi.org/10.1016/j.carbpol.2016.05.093

[40] Rosenberg, M. and Young, S.L. (1993) Food Structure Whey Proteins as Microencapsulating Agents. Microencapsulation of Anhydrous Milkfat-Structure Evaluation. Food Structure, 12, 31-41.

[41] Nandiyanto, A.B.D. and Okuyama, K. (2011) Progress in Developing Spray-Drying Methods for the Production of Controlled Morphology Particles: From the Nanometer to Submicrometer Size Ranges. Advanced Powder Technology, 22, 1-19. https://doi.org/10.1016/j.apt.2010.09.011

[42] Walton, D.E. (2000) The Morphology of Spray-Dried Particles a Qualitative View. Drying Technology, 18, 1943-1986. https://doi.org/10.1080/07373930008917822

[43] Elversson, J. and Millqvist-Fureby, A. (2005) Particle Size and Density in Spray Drying-Effects of Carbohydrate Properties. Journal of Pharmaceutical Sciences, 94, 2049-2060. https://doi.org/10.1002/jps.20418

[44] Trindade, M.A. and Grosso, C.R.F. (2000) The Stability of Ascorbic Acid Microencapsulated in Granules of Rice Starch and in Gum Arabic. Journal of Microencapsulation, 17, 169-176. https://doi.org/10.1080/026520400288409

[45] Rosenberg, M., Kopelman, I.J. and Talmon, Y. (1985) A Scanning Electron Microscopy Study of Microencapsulation. Journal of Food Science, 50, 139-144. https://doi.org/10.1111/j.1365-2621.1985.tb13295.x

[46] Janiszewska, E. and Włodarczyk, J. (2013) Influence of Spray Drying Conditions on Beetroot Pigments Retention after Microencapsulation Process. Acta Agrophysica, 20, 343-356.

[47] Rocha, G.A., Fávaro-Trindade, C.S. and Grosso, C.R.F. (2012) Microencapsulation of Lycopene by Spray Drying: Characterization, Stability and Application of Microcapsules. Food and Bioproducts Processing, 90, 37-42. https://doi.org/10.1016/j.fbp.2011.01.001

[48] Kim, Y.D. and Morr, C.V. (1996) Microencapsulation Properties of Gum Arabic and Several Food Proteins: Spray-Dried Orange Oil Emulsion Particles. Journal of Agricultural and Food Chemistry, 44, 1314-1320. https://doi.org/10.1021/jf9503927 
[49] Domian, E. and Wąsak, I. (2008) Microencapsulation of Rapeseed Oil Based on the Spray Drying Method. Polish Journal of Food and Nutrition Sciences, 58, 477-483.

[50] Medina-Torres, L., Santiago-Adame, R., Calderas, F., Gallegos-Infante, J.A., González-Laredo, R.F., Rocha-Guzmán, N.E., Núñez-Ramírez, D.M., Bernad-Bernad, M.J. and Manero, O. (2016) Microencapsulation by Spray Drying of Laurel Infusions (Litsea glaucescens) with Maltodextrin. Industrial Crops and Products, 90, 1-8. https://doi.org/10.1016/j.indcrop.2016.06.009

[51] Türker-Kaya, S. and Huck, C.W. (2017) A Review of Mid-Infrared and Near-Infrared Imaging: Principles, Concepts and Applications in Plant Tissue Analysis. Molecules, 22, 168. https://doi.org/10.3390/molecules22010168

[52] Bouaziz, F., Koubaa, M., Barba, F.J., Roohinejad, S. and Chaabouni, S.E. (2016) Antioxidant Properties of Water-Soluble Gum from Flaxseed Hulls. Antioxidants, 5, 26. https://doi.org/10.3390/antiox5030026

[53] Mohamed, M.A., Jaafar, J., Ismail, A.F., Othman, M.H.D. and Rahman, M.A. (2017) Fourier Transform Infrared (FTIR) Spectroscopy. In: Membrane Characterization, Elsevier B.V., New York, 3-29. https://doi.org/10.1016/B978-0-444-63776-5.00001-2

[54] Robert, P., Gorena, T., Romero, N., Sepulveda, E., Chavez, J. and Saenz, C. (2010) Encapsulation of Polyphenols and Anthocyanins from Pomegranate (Punica granatum) by Spray Drying. International Journal of Food Science and Technology, 45, 1386-1394. https://doi.org/10.1111/j.1365-2621.2010.02270.x

[55] Da Rosa, C.G., Borges, C.D., Zambiazi, R.C., Rutz, J.K., da Luz, S.R., Krumreich, F.D., Benvenutti, E.V. and Nunes, M.R. (2014) Encapsulation of the Phenolic Compounds of the Blackberry (Rubus fruticosus). Food Science and Technology, 58, 527-533. https://doi.org/10.1016/j.lwt.2014.03.042

[56] Kuck, L.S. and Noreña, C.P.Z. (2016) Microencapsulation of Grape (Vitis labrusca var. Bordo) Skin Phenolic Extract Using Gum Arabic, Polydextrose, and Partially hydrolyzed Guar Gum as Encapsulating Agents. Food Chemistry, 194, 569-576. https://doi.org/10.1016/j.foodchem.2015.08.066 